\title{
Breast augmentation surgery using an inframammary fold incision in Southeast Asian women: Patient-reported outcomes
}

\author{
Charles Randquist ${ }^{1}$, Yong Chen Por $^{2,3}$, Vincent Yeow ${ }^{2,3}$, Joy Maglambayan ${ }^{4}$, Susan Simonyi ${ }^{4}$ \\ ${ }^{1}$ Victoriakliniken, Saltsjöbaden, Sweden; ${ }^{2}$ DREAM Aesthetics \& Plastic Surgery, Singapore; ${ }^{3}$ KK Women's and Children's Hospital, \\ Singapore; ${ }^{4}$ Allergan Singapore Pte Ltd, Singapore
}

Background This analysis presents patient-reported outcomes of breast augmentation procedures performed in Singapore using an inframammary fold incision and the " 5 Ps" best practice principles for breast augmentation. These data are the first of their kind in Southeast Asian patients.

Methods Through a retrospective chart review, patients who underwent primary breast augmentation with anatomical form-stable silicone gel breast implants using an inframammary fold incision were followed for $\geq 6$ months postoperatively. The BREAST-0 Augmentation Module (scores standardized to 0 [worst] - 100 [best]) and Patient and Observer Scar Assessment Scale (POSAS; 1 [normal skin] to 10 [worst scar imaginable]) were administered. Responses were summarized using descriptive statistics. Patient-reported events were collected. Results Twenty-two Southeast Asian patients (mean age, 35.1 years) completed $\geq 1$ postoperative BREAST- 0 and POSAS assessment and were assessed 11 months to 5.5 years postoperatively. The mean postoperative BREAST- 0 satisfaction with breasts and psychosocial well-being scores were 69.2 and 84.0, respectively. The mean POSAS score for their overall opinion of the scar was 4.2; the mean scores for all scar characteristics ranged from 1.2 to 4.2. Over $90 \%$ of patients (20/22) said that they would recommend the procedure. Patient complaints following surgery included anisomastia (possibly pre-existing; $n=2$ ), sensory loss at the nipple $(n=2)$ or around the nipple $(n=3)$, scarring $(n=4)$, and slight capsular contracture $(n=1)$. No patients required reoperation.

Conclusions Southeast Asian patients reported high long-term satisfaction scores on the BREAST- $Q$ scale and with their scar characteristics following breast augmentation using an inframammary fold incision, and nearly all said they would recommend this procedure. No reoperations were necessary in patients assessed for up to 5.5 years postoperatively.

Keywords Asia, Southeastern / Breast implants / Mammaplasty / Patient satisfaction
Correspondence: Charles Randquist Victoriakliniken, Rosundavagen 4, SE-133 36 Saltsjöbaden, Sweden Tel: +46-853021000 Fax: +46-853021009 E-mail: charles.randquist@ victoriakliniken.com
This study was presented at the
International Master Course on Aging
Science (IMCAS) Asia on July 21-23, Science (IMCAS) Asia on
2017, in Bali, Indonesia.

\section{INTRODUCTION}

The number of surgical cosmetic procedures performed in
Asian countries has risen dramatically over recent years, with breast augmentation becoming increasingly more common $[1,2]$. Despite this increase, clinical data on breast augmentation

Copyright (C) 2018 The Korean Society of Plastic and Reconstructive Surgeons

This is an Open Access article distributed under the terms of the Creative Commons Attribution Non-Commercial License (http://creativecommons.org/

licenses/by-nc/4.0/) which permits unrestricted non-commercial use, distribution, and reproduction in any medium, provided the original work is properly cited.

www.e-aps.org 
procedures performed in Asian women are limited [3]. The aesthetic outcomes of breast augmentations performed using an inframammary fold incision in Southeast Asian women are particularly understudied, based on the view that an inframammary fold incision is more likely to result in conspicuous scarring of the skin than an axillary or areolar incision $[3,4]$.

Approaches to planning and performing breast augmentation surgery with the goal of improving not only postoperative outcomes, but also patient experiences and satisfaction, have been described in detail $[5,6]$. One established, recognized approach for improving patient outcomes of breast augmentation is the " 5 Ps" [7-11]. The 5 Ps are best practices for surgery and preoperative planning that include (1) appropriate patient selection and thorough patient education; (2) preoperative planning, including careful assessment of the patient's measurements and features; (3) proportional thinking during implant selection; (4) performance during surgery aimed at minimizing complications and achieving a controlled long-term result; and (5) postoperative care with a 1-night postoperative stay and follow-up. The goal of the 5 Ps is to achieve predictable, reliable, and satisfying outcomes of breast augmentations; this formula has been successfully utilized and studied in inframammary fold-based augmentations [7-11].

The aim of this study was to present first-in-kind patient-reported outcomes from Southeast Asian patients following breast augmentations performed via an inframammary fold incision using the 5 Ps.

\section{METHODS}

A retrospective chart review was performed to evaluate data from women who underwent primary breast augmentation with anatomical form-stable silicone gel breast implants in a dual plane using an inframammary fold incision during surgical workshops at a hospital in Singapore from April 1, 2009 to April 30,2013 . The surgical workshops implemented the 5 Ps $[9,10]$. Patients were followed for 6 months to 5.5 years after surgery, and a subanalysis of outcomes in Southeast Asian patients was conducted.

\section{Primary analysis}

The primary objective of this study was to assess patient satisfaction using scales from the validated BREAST-Q Augmentation Module and to assess patient and physician satisfaction using the Patient and Observer Scar Assessment Scale (POSAS). BREAST-Q questionnaires were administered postoperatively and included scales for the patient's satisfaction with her breasts (17-item scale on issues related to breast appearance, softness, size, amount of cleavage, scar appearance, and extent of implant rippling) $[12,13]$, psychosocial well-being (9-item scale on issues related to confidence in social settings, feeling attractive, self-assurance, and self-confidence), physical well-being (7-item scale on issues related to breast pain, difficulty lifting, and discomfort with physical activity), and sexual well-being (5-item scale on issues related to confidence in sexual activity and feelings of attractiveness) [12-14]. The 6-item POSAS (1-10 scale; $1=$ normal skin to $10=$ worst scar imaginable) [15] was administered postoperatively and assessed scar characteristics compared with normal skin; the patient's overall opinion of the scar was determined.

\section{Secondary analysis}

Secondary analyses included investigator-assessed responses to the Vancouver Scar Scale, which rates individual degrees of scar vascularity, height/thickness, pliability, and pigmentation, for a total combined score of 0 to $13[16,17]$, as well as to the Manchester Scar Scale (5-18 scores; $5=$ best to $18=$ worst) $[17,18]$.

\section{Other analyses}

The Breast Evaluation Questionnaire, a validated 55-item questionnaire assessing quality of life and breast satisfaction outcomes in breast surgery patients $(1-5$ scale; $1=$ very dissatisfied/uncomfortable to $5=$ very satisfied/comfortable), was administered postoperatively [19]. Patients rated comfort with their appearance in general and with the appearance of their breasts in different states of dress in the presence of other people (e.g., other women, partner, health care providers) as well as in different settings (e.g., professional, leisure, intimate).

\section{Statistical methods}

For all analyses, patients were stratified into three categories according to the interval between their surgery and the time they completed the questionnaire or scale in question: $<1.5$ years, 1.5 to 2.5 years, and $>2.5$ years. All responses were summarized using descriptive statistics. No inferential analyses were performed. Scores from the scales were summed and then standardized to 0 (worst) to 100 (best) [12].

\section{RESULTS}

A total of 31 Asian patients received breast augmentation using an inframammary fold incision. Twenty-two of the patients with recorded follow-up assessments (71.0\%, defined as 1 or more postoperative BREAST-Q and POSAS assessment) were Southeast Asian. These 22 patients composed the group whose outcomes from 11 months through 5.5 years postoperatively 
were the focus of this analysis. Table 1 summarizes the demographic characteristics of these women.

\section{BREAST-Q}

High mean postoperative BREAST-Q scores for satisfaction with breasts and for psychosocial, physical, and sexual wellbeing were achieved in this subset of Southeast Asian patients following surgery with the inframammary fold approach to breast augmentation (Fig. 1). All mean postoperative BREASTQ scores for satisfaction with breasts and for psychosocial, physical, and sexual well-being at $<1.5$ years, 1.5 to 2.5 years, and $>2.5$ years after surgery exceeded $65 \%$. Less than 1.5 years after surgery, patients reported very high levels of satisfaction with their breasts (at least 70\%) and of psychosocial, physical, and sexual well-being (in the range of $87 \%-92 \%$ ). These high scores were maintained throughout the study period, with scores at 5.5 years after surgery for psychosocial, physical, and sexual wellbeing above $80 \%$ and satisfaction with breasts persisting at near $70 \%$ for all respondents.

\section{Table 1. Demographics and baseline characteristics}

\begin{tabular}{|lc|}
\hline Characteristic & Patients $(\mathbf{n}=22)$ \\
\hline Age $(\mathrm{yr})$ & $35.1 \pm 6.03(22-45)$ \\
Height $(\mathrm{cm})$ & $160.5 \pm 5.17(152.5-172)$ \\
Weight $(\mathrm{kg})$ & $49.5 \pm 4.39(41-57)$ \\
Body mass index $\left(\mathrm{kg} / \mathrm{m}^{2}\right)$ & $19.23 \pm 1.70(15.59-21.99)$ \\
\hline \multicolumn{2}{|l}{ Values are presented as mean \pm SD (range). } \\
\hline
\end{tabular}

\section{Scar scales \\ POSAS (patient and physician)}

Patients were generally satisfied with the appearance of their inframammary fold scar, as assessed on a scale of 1 to $10(1=$ normal skin to $10=$ worst scar imaginable). More specifically, the mean scores for their overall opinion of the scar remained within the normal skin range during all intervals after surgery, except for $>2.5$ years after surgery, for which a neutral mean score of 5.0 was observed (Fig. 2). Patients' mean score for their overall opinion of the scar was 4.2, and the scores for all scar characteristics, including scar placement, ranged from 1.2 to 4.2. Patients' mean score for scar placement was 2.1, indicating that they were generally satisfied with the scar location.

Physicians' overall opinion of scars was consistent with and more favorable than that of the patients (Fig. 2). Physicians' mean scores for all scar characteristics ranged from 1.0 to 3.0.

\section{Vancouver and Manchester Scar Scales}

Most investigators reported fairly minimal scarring using the Vancouver and Manchester Scar Scales, with agreement between the two scales (Fig. 3).

\section{Patient-reported complaints and reoperation rates}

Patient-reported complaints were minimal, with one case of capsular contracture and two cases of anisomastia (possibly preexisting) reported (Table 2). No patients required reoperation over 5.5 years of postoperative follow-up.

\section{Fig. 1. Mean postoperative BREAST-0 scores}

Patients were grouped into three categories according to the interval between surgery and responding to the questionnaire: $<1.5$ years, $1.5-2.5$

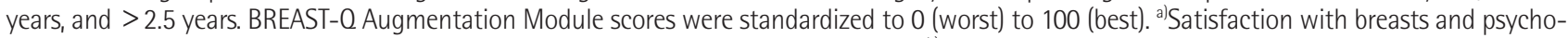
social well-being (both $n=7$ ); physical well-being and sexual well-being (both $n=6$ ); b) Satisfaction with breasts, psychosocial well-being, physical well-being, and sexual well-being (all $n=4)$; ${ }^{c}$ Satisfaction with breasts, psychosocial well-being, physical well-being, and sexual well-being $($ all $n=11) ;{ }^{d}$ Satisfaction with breasts and psychosocial well-being (both $\left.n=22\right)$; physical well-being and sexual well-being (both $\left.n=21\right)$.

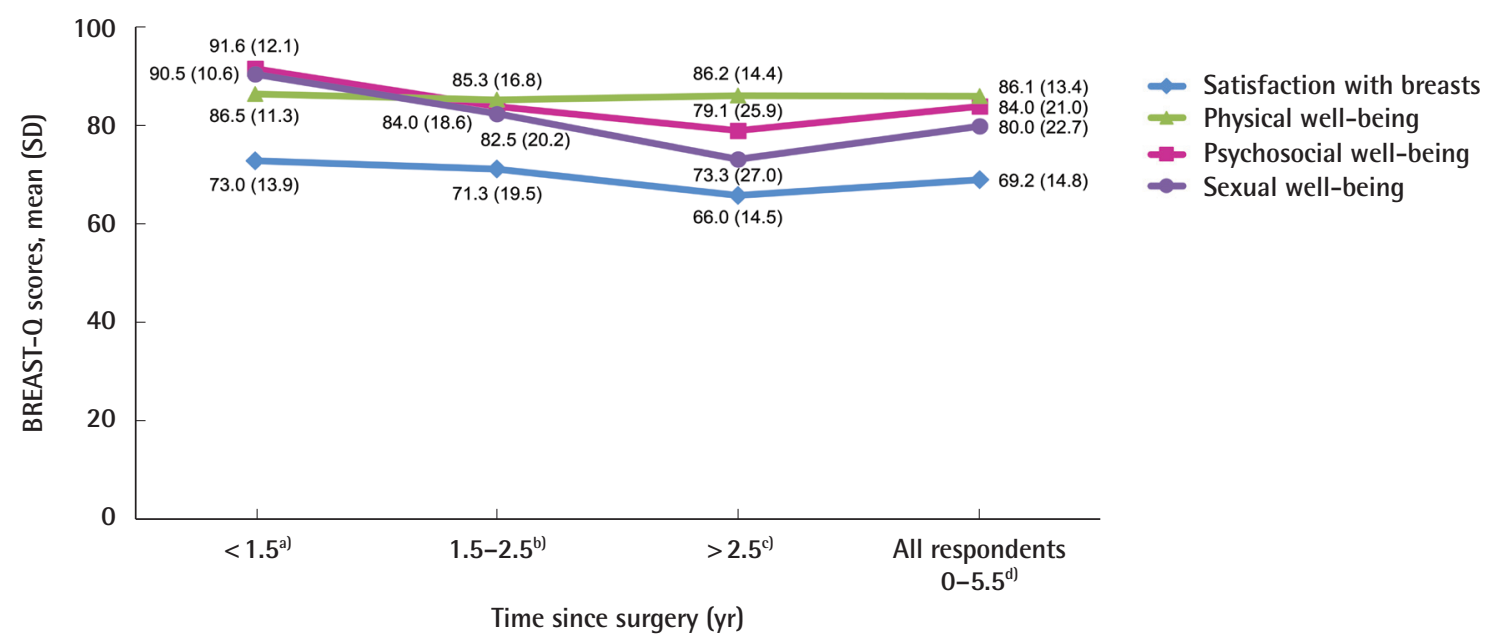




\section{Fig. 2. Mean postoperative POSAS scores}

Patients were grouped into three categories according to the interval between surgery and responding to the questionnaire: $<1.5$ years, $1.5-2.5$ years, and $>2.5$ years. Scores reported on a 1 to 10 scale ( $1=$ normal skin, $10=$ worst scar imaginable). POSAS, Patient and Observer Scar Assess-

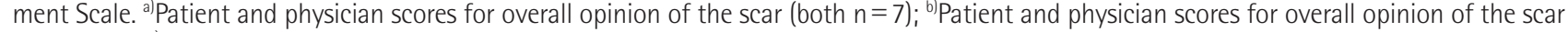

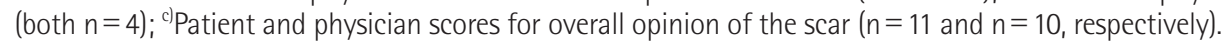

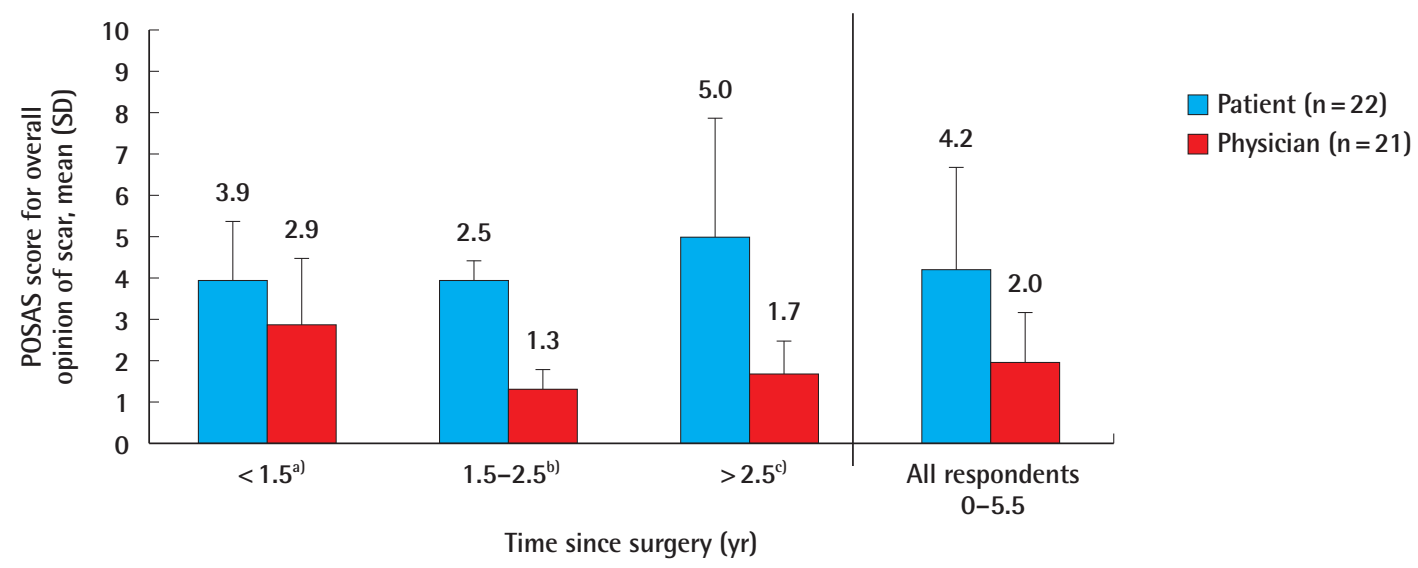

\section{Fig. 3. Mean Vancouver and Manchester Scar Scale scores}

(A) Vancouver Scar Scale scores range from 0 (best) to 13 (worst); (B) Manchester Scar Scale scores range from 5 (best) to 18 (worst) [17].
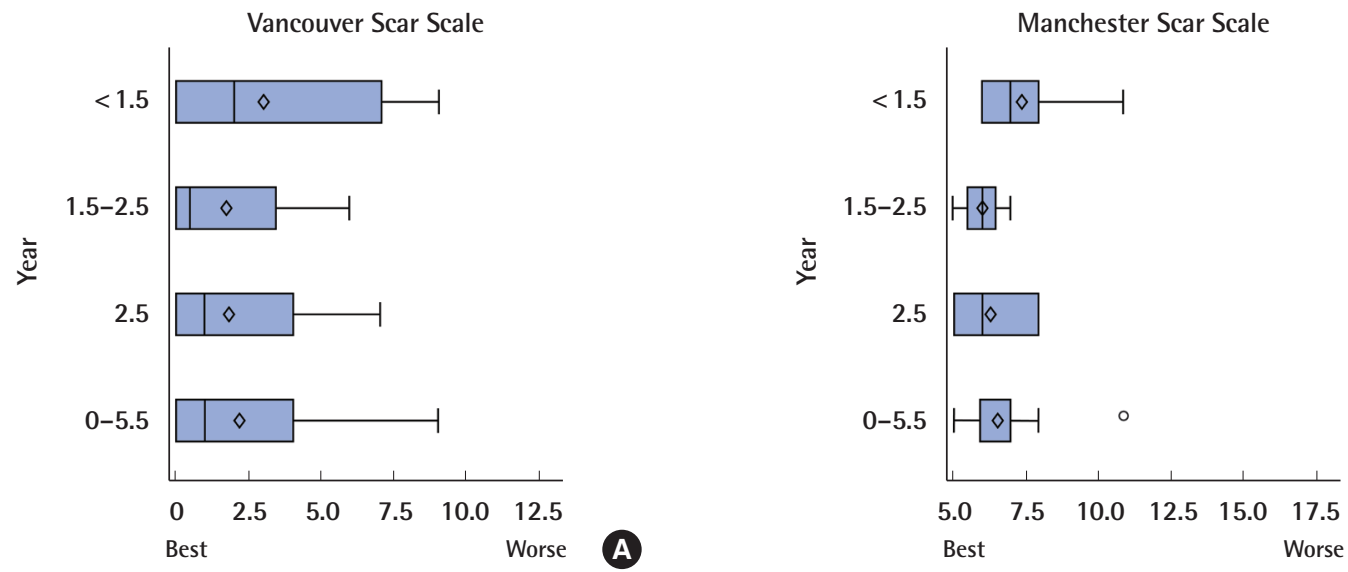

Table 2. Patient-reported complaints through 5.5 years postoperatively

\begin{tabular}{|lc|}
\hline & Patients $(\mathbf{n}=\mathbf{2 2})$ \\
\hline Scar & $4(12.9)$ \\
Sensory loss around the nipple & $3(9.7)$ \\
Sensory loss at the nipple & $2(6.5)$ \\
Anisomastia & $2(6.5)$ \\
Capsular contracture & $1(3.2)$ \\
\hline Values are presented as number (\%). & \\
\hline
\end{tabular}

\section{Breast Evaluation Questionnaire}

Patients reported high overall levels of being somewhat or very comfortable with their general appearance (Fig. 4A) as well as the appearance of their breasts (Fig. 4B), even in situations in- volving greater exposure of the body. Patients were satisfied with the characteristics of their breasts (e.g., size, shape, firmness) in a variety of social settings (Fig. 5). Similarly, patients expressed overall general satisfaction with the appearance and size of their breasts in response to the Breast Evaluation Questionnaire items relating to their own and others' perspectives of satisfaction with the appearance of their breasts and the importance of the size of their breasts (Fig. 6). All patients rated the size of their breasts as somewhat or very important to themselves, whereas importance to their siblings, parents, and friends was rated much lower than for their partners. More than $90 \%$ of patients (20/22) also reported that they would recommend the breast augmentation procedure with an inframammary incision to others. 


\section{Fig. 4. Comfort level in the presence of others}

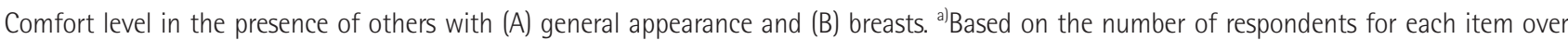
$0-5.5$ years postoperatively.

$\square$ Somewhat or very comfortable

$\square$ Somewhat or very uncomfortable, or neither comfortable nor uncomfortable

Fully dressed

With women known well With women not known well With partner

With men in general With health care provider

Alone

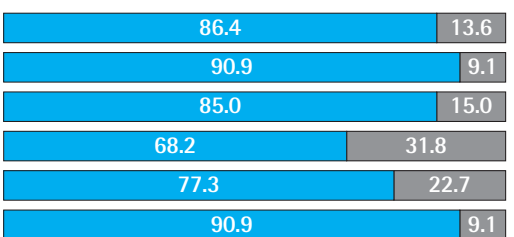

In bathing suit

With women known well With women not known well With partner

With men in general With health care provider

Alone

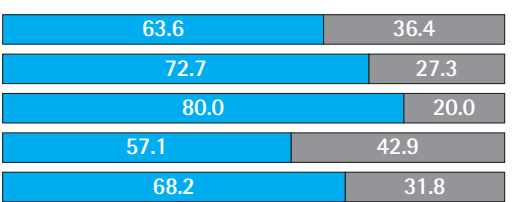

Naked

With women known well With women not known well With partner

With men in general

With health care provider

Alone

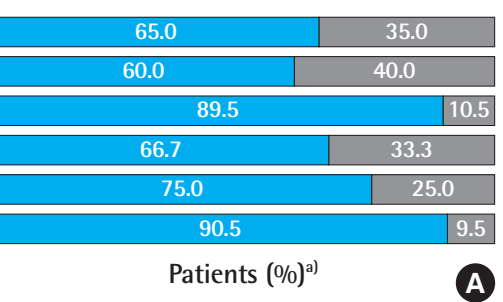

Fully dressed

With women known well With women not known well With partne With men in general With health care provider Alone

\begin{tabular}{|c|c|}
\hline 81.0 & 19.0 \\
\hline 85.7 & 14.3 \\
\hline 89.5 & 10.5 \\
\hline 85.0 & 15.0 \\
\hline 85.7 & 14.3 \\
\hline 85.7 & 14.3 \\
\hline
\end{tabular}

In bathing suit

With women known wel With women not known wel With partne With men in general With health care provider Alone

\begin{tabular}{|c|c|}
\hline 68.4 & 31.6 \\
\hline 84.2 & 15.8 \\
\hline 83.3 & 16.7 \\
\hline 68.4 & 31.6 \\
\hline 78.9 & 21.1 \\
\hline
\end{tabular}

Naked

With women known well With women not known well With partne With men in general With health care provider Alone

\begin{tabular}{|c|c|}
\hline 77.8 & 22.2 \\
\hline 72.2 & 27.8 \\
\hline 83.3 & 16.7 \\
\hline 70.6 & 29.4 \\
\hline 78.9 & 21.1 \\
\hline 85.0 & 15.0 \\
\hline Patients (\%) ${ }^{\text {a) }}$ & B \\
\hline
\end{tabular}

\section{Fig. 5. Satisfaction with breasts in various social settings}

a) Based on the number of respondents for each item over 0-5.5 years postoperatively.

Somewhat or very satisfied

$\square$ Somewhat or very dissatisfied, or neither satisfied nor dissatisfied

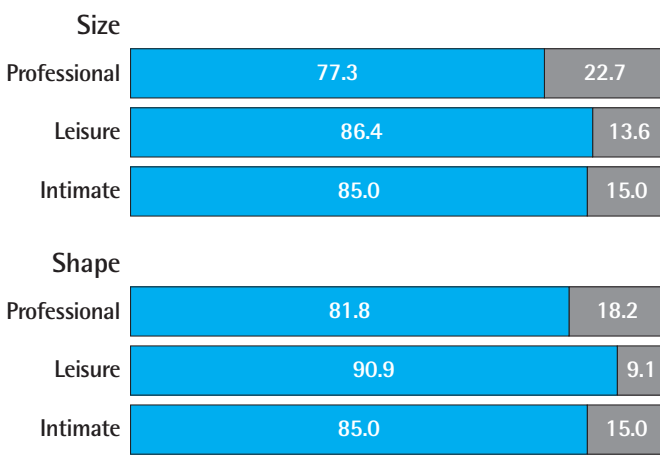

Firmness

\begin{tabular}{r|c|c|}
\cline { 2 - 3 } Professional & 63.6 & 36.4 \\
\cline { 2 - 3 } Leisure & 63.6 & 36.4 \\
\cline { 2 - 3 } Intimate & 65.0 & 35.0 \\
\cline { 2 - 3 } & &
\end{tabular}

Patients $(\%)^{a)}$

\section{DISCUSSION}

This is the first report in the literature exploring long-term patient satisfaction among Southeast Asian women who received breast augmentation with an inframammary fold incision. In this analysis, which followed patients for up to 5.5 years after breast augmentation, patients reported high satisfaction with their surgery, as reflected by their scores on multiple scales of the BREAST-Q Augmentation Module [20]. Patient and physician scar assessments were similarly favorable, and these findings were substantiated through three separate scar evaluation scales.

The postoperative BREAST-Q findings in this study showed that, from $<1.5$ years through 5.5 years after surgery, the mean scores for satisfaction with breasts remained consistently favorable, at approximately $70 \%$ for all respondents. The mean scores for physical, psychosocial, and sexual well-being were also high, ranging from $79.1 \%$ to $91.6 \%$. Although no baseline BREASTQ scores were recorded for direct comparisons, the postoperative BREAST-Q scores reported in this sample of patients provide reliable evidence of high levels of satisfaction with breast augmentation [21] and are similar to those reported in much 


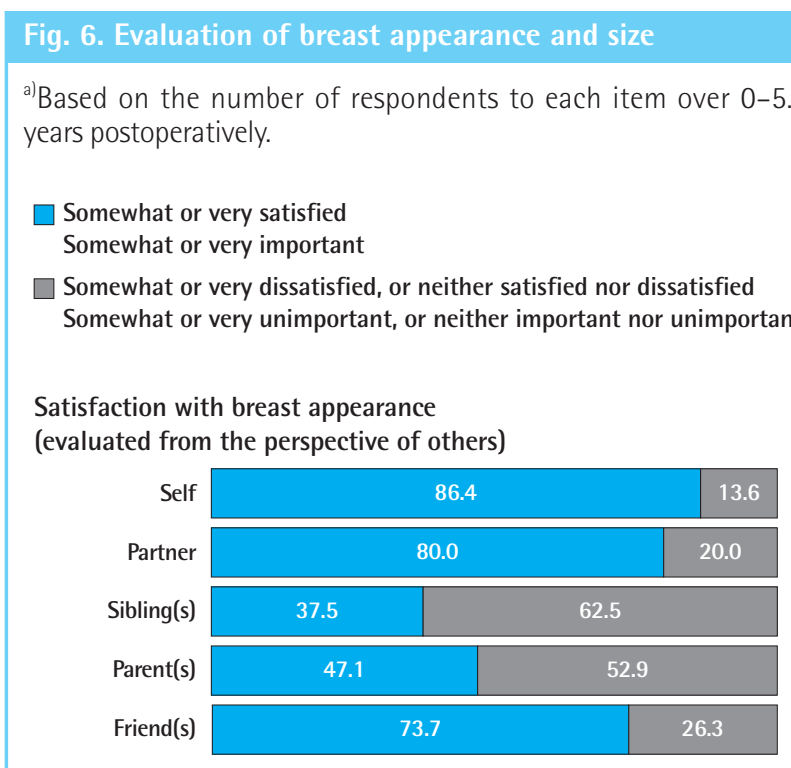

Importance of breast size

(evaluated from the perspective of others)

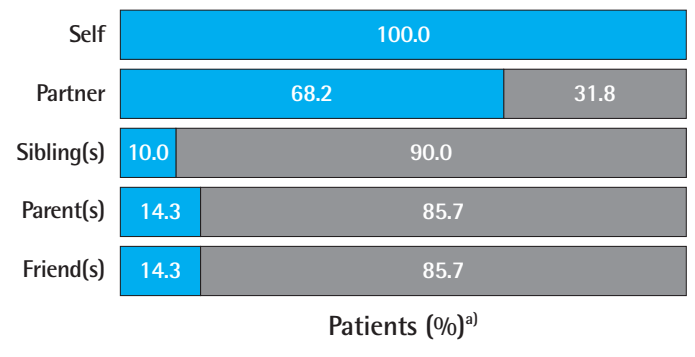

larger studies that evaluated BREAST-Q scores before and after breast augmentation $[14,22]$. In those studies, scores from 6 weeks to 4 years postoperatively were in the $80 \%$ to $86 \%$ range for satisfaction with breasts and the $71 \%$ to $90 \%$ range for physical, psychosocial, and sexual well-being [14,22]. Moreover, the postoperative BREAST- $Q$ augmentation scores in the current study are similar to, if not better than, normative BREAST-Q augmentation scores [20]. The normative scores for more than 1,200 women were reported as $54 \%$ for satisfaction with breasts, $66 \%$ for psychosocial well-being, $49 \%$ for sexual well-being, and $86 \%$ for physical well-being, whereas the postoperative scores in the present study were $69.2 \%, 84.0 \%, 80.0 \%$, and $86.1 \%$, respectively. Together, the results of these previously published studies support the conclusion that the patients in the current study reported a considerable level of satisfaction with breast augmentation performed using an inframammary fold incision.

The high level of satisfaction in regard to scar appearance in this study is meaningful, considering concerns about scarring with breast augmentation surgery in Asian women; namely, the perception exists that Asian skin is prone to hyperpigmentation at and surrounding incision sites $[3,4]$. As a result, it is much more common for Asian women to receive breast augmentations using axillary and areolar incisions, as these are perceived to result in less noticeable scars than inframammary fold incisions due to an allegedly more easily camouflaged placement $[3,4]$. However, the inframammary fold incision is the most widely used approach in breast augmentation because it allows more favorable visibility and surgical control, and results in less trauma to the adjacent tissue than periareolar, transaxillary, and transumbrical incisions. The benefits of using an inframammary fold incision may lead to reduced operating times and enhanced patient recovery [7]. This study has shown that both patients and their physicians were satisfied with the location and the appearance of scars after breast augmentation with an inframammary fold incision. These findings suggest that a reconsideration of the incision used in breast augmentation surgery in this patient population is warranted.

The majority of patients were comfortable with their general appearance and the appearance of their breasts after surgery, and nearly all patients said they would recommend this type of surgery. Similarly, the majority of patients were comfortable with their general appearance and the appearance of their breasts postoperatively in situations involving greater exposure of the body (i.e., being naked or wearing a bathing suit). Patient comfort levels with their appearance in the presence of other women, both known and unknown to them, were positive; most of the patients reported being comfortable with the appearance of their breasts in front of other women in all states of dress, and nearly all reported being comfortable with their general appearance when fully dressed in the presence of women they did not know well. This is an intriguing finding because perceptions of and self-comparisons with other women have been noted to play a role in women's reasons for seeking breast augmentation [23].

Very few patients reported any complaints, and no reoperations were required in these patients over the course of 5.5 years of postoperative follow-up. The absence of reoperations is a notable result in light of previous studies that have identified rates of surgical revisions of more than $12 \%$ following breast augmentation with anatomical silicone gel breast implants with similar follow-up time periods. These revisions have often arisen from a need to correct implant malposition, capsular contracture, scarring, ptosis, hematoma or seroma, or unsatisfactory size or shape $[24,25]$. The lack of augmentation revisions in the current study again underscores the patients' high satisfaction with the inframammary fold incision and the low incidence of complications. The use of the 5 Ps best practices may have helped to minimize complications and the need for reoperations.

The limitations of this study include the absence of baseline 
BREAST-Q scores, a small sample size, and incomplete followup data for all 22 patients. However, given the underrepresentation of Southeast Asian patients in the literature, the previously unexplored success rate with inframammary fold incisions in this population, and the extended duration of the study, it is reasonable to conclude that these data provide reliable evidence of favorable long-term outcomes with inframammary fold-based breast augmentations in this population.

Southeast Asian patients were highly satisfied more than 1 year after breast augmentation surgery using the inframammary incision approach based on BREAST-Q scores and scar characteristics. This study provides valuable insights that can inform breast augmentation techniques and the choice of an incision approach for use with breast implants in Asian women.

\section{NOTES}

\section{Conflict of interest}

Charles Randquist, Yong Chen Por, and Vincent Yeow consult and conduct research for Allergan. Joy Maglambayan and Susan Simonyi are employees of Allergan. This study was sponsored by Allergan plc, Dublin, Ireland. Writing and editorial assistance was provided to the authors by Regina Kelly of Peloton Advantage (Parsippany, NJ, USA) and was funded by Allergan plc, Dublin, Ireland. All authors meet the ICMJE authorship criteria. Neither honoraria nor payments were made for authorship.

\section{Ethical approval}

The study was approved by the SingHealth Centralised Institutional Review Board D for KK Women's and Children's Hospital (CIRB No. 2015/2155) and performed in accordance with the principles of the Declaration of Helsinki. The informed consent was waived.

\section{REFERENCES}

1. International Society of Aesthetic Plastic Surgery. ISAPS International Survey on Aesthetic/Cosmetic Procedures Performed in 2011 [Internet]. Hanover, NH; c2012 [cited Oct 28, 2016]. Available from https://www.isaps.org/wpcontent/uploads/2017/10/ISAPS-Results-Procedures-2011-1. pdf.

2. International Society of Aesthetic Plastic Surgery. ISAPS International Survey on Aesthetic/Cosmetic Procedures Performed in 2015 [Internet]. Hanover, NH; c2016 [cited Oct 28, 2016]. Available from https://www.isaps.org/wpcontent/uploads/2017/10/2016-ISAPS-Results-1.pdf.

3. Zelken J, Cheng MH. Asian breast augmentation: a system- atic review. Plast Reconstr Surg Glob Open 2015;3:e555.

4. Cheng MH, Huang JJ. Augmentation mammaplasty in Asian women. Semin Plast Surg 2009;23:48-54.

5. Adams WP Jr, Small KH. The process of breast augmentation with special focus on patient education, patient selection and implant selection. Clin Plast Surg 2015;42:413-26.

6. Heden P, Brown MH, Luan J, et al. Delphi study consensus recommendations: patient selection and preoperative planning measurements for Natrelle 410. Plast Reconstr Surg Glob Open 2015;3:e556.

7. Kim YJ, Kim YW, Cheon YW. Prevention of implant malposition in inframammary augmentation mammaplasty. Arch Plast Surg 2014;41:407-13.

8. Schwartz MR. Algorithm and techniques for using Sientra's silicone gel shaped implants in primary and revision breast augmentation. Plast Reconstr Surg 2014;134(1 Suppl):18S27S.

9. Randquist C. My confession after 14 years of experience with form stable high cohesive silicone gel implants. Can J Plast Surg 2010;18:116.

10. Randquist C, Gribbe O. Highly cohesive textured form stable gel implants: principles and technique. In: Hall-Findlay EJ, Evans GR, Kim KK, editors. Aesthetic and reconstructive surgery of the breast. New York: Saunders Elsevier; 2010. p. 339-55.

11. Atiyeh BS, Dibo SA, Nader M, et al. Preoperative assessment tool for the planning of inframammary incision and implant profile in breast augmentation. Aesthetic Plast Surg 2014;38:878-86.

12. Pusic AL, Reavey PL, Klassen AF, et al. Measuring patient outcomes in breast augmentation: introducing the BREASTQ augmentation module. Clin Plast Surg 2009;36:23-32.

13. Cano SJ, Klassen AF, Scott AM, et al. A closer look at the BREAST-Q ${ }^{\odot}$. Clin Plast Surg 2013;40:287-96.

14. Alderman AK, Bauer J, Fardo D, et al. Understanding the effect of breast augmentation on quality of life: prospective analysis using the BREAST-Q. Plast Reconstr Surg 2014; 133:787-95.

15. The Patient and Observer Scar Assessment Scale. The scale [Internet]. c2017 [cited Apr 27, 2017]. Available from http://www.posas.org/the-posas/the-scale/.

16. Sullivan T, Smith J, Kermode J, et al. Rating the burn scar. J Burn Care Rehabil 1990;11:256-60.

17. Fearmonti R, Bond J, Erdmann D, et al. A review of scar scales and scar measuring devices. Eplasty 2010;10:e43.

18. Beausang E, Floyd H, Dunn KW, et al. A new quantitative scale for clinical scar assessment. Plast Reconstr Surg 1998; 102:1954-61. 
19. Anderson RC, Cunningham B, Tafesse E, et al. Validation of the Breast Evaluation Questionnaire for use with breast surgery patients. Plast Reconstr Surg 2006; 118:597-602.

20. Mundy LR, Homa K, Klassen AF, et al. Normative data for interpreting the BREAST-Q: augmentation. Plast Reconstr Surg 2017; 139:846-53.

21. Cohen WA, Mundy LR, Ballard TN, et al. The BREAST-Q in surgical research: a review of the literature 2009-2015. J Plast Reconstr Aesthet Surg 2016;69:149-62.

22. Alderman A, Pusic A, Murphy DK. Prospective analysis of primary breast augmentation on body image using the BREAST-Q: results from a nationwide study. Plast Reconstr
Surg 2016; 137:954e-960e.

23. Sarwer DB, LaRossa D, Bartlett SP, et al. Body image concerns of breast augmentation patients. Plast Reconstr Surg 2003;112:83-90.

24. Bengtson BP. The Natrelle 401 highly cohesive form-stable gel implant for primary breast augmentation. In: Spear SL, Willey SC, Robb GL, et al., editors. Surgery of the breast: principles and art. 4th ed. Baltimore: Lippincott Williams \& Wilkins; 2017.p. 1346-65.

25. Maxwell GP, Van Natta BW, Murphy DK, et al. Natrelle style 410 form-stable silicone breast implants: core study results at 6 years. Aesthet Surg J 2012;32:709-17. 